\title{
Public libraries as anchor institutions in smart communities: Current practices and future development
}

\author{
Shannon Mersand \\ University at Albany, State University of New York \\ smersand@albany.edu \\ Emmanuel Udoh \\ University at Albany, State University of New York \\ eudoh@albany.edu
}

\begin{abstract}
Local governments around the world are exploring different strategies to become smarter: more efficient, sustainable, and highly interconnected. However, many actors outside government need to be involved too. For instance, public libraries have the potential to play a very important role in the development of smart and connected communities, due to their strong legitimacy in the eyes of citizens and the types of services and programs they are already providing, which in many cases go well beyond what could be considered traditional library services. This paper analyzes innovative practices in public libraries and argue that they already show the potential of public libraries to become catalysts for smart and connected communities. Together, these innovations represent an opportunity for governments and communities to engage and a new way to think about public libraries as very important actors in smart community initiatives.
\end{abstract}

\section{Introduction}

Technological innovation can help cities and communities meet the current challenges of governance, tackle complex social problems, improve urban and rural environments, become more competitive, and address sustainability concerns. Smart strategies have therefore emerged in many communities as a way to improve government services, but also overall quality of life for citizens. The majority of these strategies focus on how technology and data can save hard earned taxpayer money, vastly

\author{
Mila Gasco-Hernandez \\ University at Albany, State University of New York \\ mgasco@ctg.albany.edu
}

\author{
J. Ramon Gil-Garcia \\ University at Albany, State University of New York \\ \& Universidad de las Americas Puebla \\ jgil-garcia@ctg.albany.edu
}

improve government decision making and current services, and enable new types of services only dreamed of before. In the US, such smart strategies have become a national priority with increased federal funding encouraging a community of data scientists, technologists, and civic leaders to harness the growing data revolution, low-cost sensors, and research partnerships to unlock new solutions that can benefit society. While acknowledging this broader community partnership, more often than not, these initiatives are industry- and government-driven with much less focus on identifying community demands that are allinclusive and address that community's ability to benefit from and utilize smart city technologies and services [1][2][3]. Moreover, it is also evident that community institutions such as public libraries have been largely left out of the ongoing dialogue about smart cities and communities [4].

The idea that public libraries are necessary partners in community development has been circulating in the planning literature for decades [5][6][7]. In the specific case of smart cities, and particularly after 2009 in the United States, public libraries have widely been used as anchor institutions that could extend connectivity and the benefits of robust broadband [5]. In parallel, these libraries have also embraced the digital era, becoming technological hubs: it is no surprise to find public computers and free WiFi in libraries today; also e-books and online databases for research and an array of other online resources. Further, libraries are using Facebook and Twitter to connect with patrons.

Yet, as a very important element of the digital, knowledge and creative infrastructures of smart communities, public libraries could further play a critical role in involving the community and in addressing its needs, issues and interests. They could offer a new generation of library services that could be 
integrated with the city infrastructure and that could extend public libraries role as community anchors and as information literacy hubs in smart cities and communities. However, still, more knowledge and practical insights are needed on public libraries strategies, programs, services and tools aimed at engaging citizens in smart and innovative cities and communities.

This paper aims to shed light on this topic by identifying innovative practices across the United States that show the potential role of public libraries as anchor institutions in smart community initiatives. Specifically, our main research question is: what innovative strategies, programs, services, and tools are public libraries already implementing that show their potential role as important actors in smart community initiatives?

\section{Smart cities, communities, and public libraries}

This section presents the conceptual framework of our study, based on the literature on smart cities and communities and on the role of public libraries as anchor institutions in smart community initiatives.

\subsection{From smart cities to smart communities}

Though still an emergent concept without a universally accepted meaning [8][9][10], there is consistency in how different definitions describe what a smart city does [11]:

- Adopt a global/integral view of the city, which materializes in different types of initiatives, from waste management to traffic control to water management.

- Integrate a double perspective, technological and human. Technology is key in the development of smart cities (and, therefore, it is the tool par excellence); however, smart cities have to be developed for, by, and with citizens. As a result, urban governance and participation processes, as well as investments in human and social capital, are inherent attributes of a smart city.

- Pursue a triple goal: 1) to improve the efficiency of urban operations, 2) to improve citizens quality of life, and 3 ) to promote the local economy, while maintaining environmental sustainability.

While most of the early definitions of a smart city were focused on technology [12], the view above shows that, currently, there is recognition that smart cities are socio-technical systems or, in other words, complex adaptive systems with physical (physical resources) and social components (human elements) [13], that need to be governed as such.

The topic of smart cities is being studied in different academic disciplines such as urban geography, urban sociology, computer science, information systems research, spatial planning science, and lately public management. The existing studies are diverse. Some suggest multidimensional frameworks that propose a definition of a smart city by looking at some of its most important features (e.g. [14][15][8][16]. Some of these studies produce rankings that benchmark how cities are becoming smart. Some other studies describe and analyze specific case studies (e.g. [17][18][19][20][21][22]). Finally, there are also conceptual articles that explore important characteristics in the design and implementation of smart cities initiatives, such as the use of technology or smart city governance (e. g. [9][23][24][25] [26]).

Although smartness has been traditionally associated with urban environments, lately, there is stronger emphasis on the concept of smart communities. On one hand, this is the result of recognizing the existence of several contexts that can benefit from the use of smart technologies: there exists a continuum of groups of people from localities or villages to communities, communes, towns, places, cantons, cities, and megacities [27][28]. On the other hand, it is the consequence of conceptualizing smartness beyond technology and in relation to the people living in those communities, who are united by common goals, interests, and challenges [29]. Building on the notion of community informatics [30], smart communities can be seen as enabling and empowering citizens and supporting the individual and communal quests for wellbeing [31].

Interestingly, the concept smart community is not new. The Smart Communities movement dates back to the late 1990s [25]. Based on Industry Canada's definition, Nam \& Pardo [25] define a smart community as "a community broadly ranging from a small neighborhood to a nation-wide community of common or shared interest, whose members, organizations and governing institutions are working in partnership to use IT to transform their circumstances in significant ways" [25, pp. 286].

Coe et al [32] identify and discuss the components of smart communities, namely, geography (proximity), technology (networking and connectivity), collective intelligence (mobilization), and social learning (continuous learning). According to the authors, the participation of the community's stakeholders is key in the development of smart communities. Nam and Pardo [25] also refer to the importance of smart governance in the success of smart community 
initiatives, meaning the engagement of various stakeholders in decision-making processes and the production and delivery of public/social services. Despite their contribution, these articles only refer to specific community's actors such as governments, businesses, and citizens. Nothing is said about the role of other partners in the development of smart communities, such as anchor institutions, that is, firmly community-rooted organizations, such as universities, hospitals, public libraries, and other place-based powerhouses.

\subsection{The role of public libraries as anchor institutions in smart community initiatives}

Anchor institutions are organizations rooted in their local communities by mission, invested capital, and/or relationships to customers, employees, vendors and clientele. They include schools, libraries, museums, healthcare organizations, and other not-for-profit organizations that serve and support the community [33]. Recent studies show that these organizations can be considered critical indicators and shapers of a community's socio-economic wellbeing. For instance, Harkavy [34] explores the role of American urban universities in achieving health equity in inner cities. Similarly, Ehlenz [35] studies how the University of Pennsylvania has been key in addressing neighborhood deterioration.

Anchor institutions seem to play an important role in bridging the digital divide too. Goodman [5], for example, shows the role of anchors institutions in extending connectivity and robust broadband, particularly in the context of smart cities. She argues that reaching the goals of a broadband policy necessarily requires the involvement of civil society organizations, such as public libraries. On the same line is the work of Mandel et al [36] who discuss the role of anchor institutions in rural Florida in the planning, development, implementation, and assessment of broadband deployment and adoption.

Although much of the work on anchor institutions has focused on the role of colleges and universities, some studies have started to emphasize how public libraries are becoming community anchors as a result of their role in civic engagement [37][38] or, in Hildreth's words, of their "unique ability to strengthen civic life, understand and respond to community needs, and knit community members together through common experiences and shared interests" [39, pp. 44]. Moxley \& Abbas [40], for example, argue that, increasingly, libraries serve as community anchors for at-risk and vulnerable populations including people who are unemployed, immigrating or seeking refuge, homeless or in re-entry from incarceration. Research also refers to public libraries as spaces where citizens gather to participate in different activities. Lenstra [41], for example, studies the opportunities public libraries provide for yoga practice for both youth and adults. Similarly, Aldrich [42] explores how public libraries can be used to increase parent engagement in prekindergarten classrooms and programs.

The notion of public libraries playing a key role in community civic engagement can also be linked to Oldenburg's [43] [44] idea of third places, (separate from the two usual social environments of home, "first place," and the workplace, "second place"), which are key for civil society, democracy, civic and cultural engagement, lifelong learning, digital inclusion, and establishing feelings of a sense of place and identity.

Digital inclusion is one of the important roles that public libraries can play as anchor institutions in their communities [45] [46][47]. It has also been one of the more frequent topics in the literature on anchor institutions. Actually, the popularization of the idea of public libraries as community anchors was the result of the 2010 National Broadband Plan, which focused on the critical role libraries played in providing access to public computers and high-speed Internet. In rural and low-income urban neighborhoods, this service was found to be a particularly valuable lifeline for the community [39][5][48].

But public libraries can go beyond the provision of access to computers and to the Internet. Goodman [5] states that they can further serve the community by becoming techno-centric hubs that may help the jobless find employment, create and support maker labs for entrepreneurs to experiment in innovation, support digital literacy and other training programs, and advance e-government and citizen engagement. Gorichanaz \& Turner [49] and Jerkov et al [6] describe public libraries as information literacy hubs, where new technologies can be experimented with and new concepts related to technology grasped. Jerkov et al. [6] also believe that their focus is particularly interesting in relation to the development of smart communities. In addition, they argue that this perspective will require librarians to play new roles: librarians become facilitators of communication among users. Instead of being the ones who select the data stored in books for preservation and use, librarians become head hunters who select and encourage those users willing to share their knowledge with other users. In the smart library, librarians tap into specific knowledge in order to provide services to other users [6, pp. 28].

Mainka et al [50] also explore the wider role public libraries can play in the knowledge economy and that includes providing free e-resources and digital reference services, spaces for children, rooms for 
learning and getting together, modular working spaces, free $\mathrm{WiFi}$, and serving as a landmark architecture for the city. That is, according to these authors, public libraries role may be two-fold: 1) to support citizens and other stakeholders in the community through digital services and 2) to provide social spaces that enable more interactions among different stakeholders. In a more recent work, Mainka et al. [51] go deeper in the interaction component and conceptualize public libraries as open spaces where several stakeholders gather to co-create better services.

Other authors have made additional contributions. In their work, Wheaton \& Murray [52] emphasize the role of public libraries as knowledge brokers, providing reliable sources of knowledge to solve community problems. Baryshev et al [53] use the concept of smart library and define it in relation to a smart environment, mobile access (or availability of all digital service types across all locations), creation of new knowledge (i.e. leveraging the collective creativity of expert groups and using social networks), active (i.e. interconnected) content, and adaptability to the level and need of the user.

Although the existing studies recognize the need to make libraries an essential part of digital and smart community initiatives, they only offer limited help in understanding specific public libraries strategies, programs, services and tools aimed at engaging communities in smart initiatives. Further, these works make evident the lack of studies providing an in-depth view on the benefits as well as the challenges, risks, costs, and unintended consequences that public libraries could face by incorporating these into their role as community anchors. We can therefore conclude that more knowledge and practical insights are needed to further understand the role of public libraries as community anchors in the development of smart communities. Furthermore, research is also needed on how public libraries position themselves as community catalysts acting to spark innovation and positive change [54].

\section{Methods and data}

Given the scarce literature on the role of libraries as community anchors in smart communities, our paper aims at contributing to the field by identifying innovative practices across the United States that show such potential role. We conducted an environmental scan with the aim of identifying innovative strategies, programs, services, and tools that could help us understand the potential role of public libraries as community anchors in smart communities initiatives and that could, therefore, inform further research on this topic.
The environmental scan was based on two major information gathering activities. First, to assure comprehensive coverage of publicly available information, we conducted targeted searches of content available on the Internet using Google.com that directed us to several sources of information, including public libraries websites, news media, government documents, library publications, and library organizations. In addition, we conducted a general literature search on public libraries and smart communities related themes to uncover review articles or other publications that characterized the current state of the topic. This first activity resulted in the identification of thirty-two branch, stand alone and system libraries in a variety of municipalities including counties, large cities, mid-sized cities, small sized cities, large suburbs, and smaller municipalities.

Second, we directly contacted individuals at the identified libraries in order to gain access to unpublished information or publications that were not readily available through public source as well as to collect in-depth information about the initiatives we had already learned about during the first stage. Following an inductive approach, the information was categorized according to five dimensions: infrastructure, technology, programs and services, partnerships, and citizen engagement.

\section{Findings: Innovations in public libraries}

In this section we will discuss each of the five dimensions, and then provide a discussion of innovations that stood out as incorporating multiple dimensions.

\subsection{Infrastructure}

Infrastructure is defined as the physical and organizational structures and facilities that are needed for operation. These may include fixed and mobile assets, as well as virtual structures. Each of the libraries we examined had both a physical presence in the form of a building space as well as a virtual presence in the form of a website. They all offered a web based public access catalog, and most offered basic outreach services like books by mail.

In addition to children's and teen rooms, many libraries have dedicated computer labs, meeting rooms, study rooms and community rooms that are multipurpose. Libraries are also creating makerspaces, FabLabs and digital media studios, places where community members can interact with equipment, technology and other materials to create and innovate. These spaces are targeted at different community residents and their specific needs. In some 
communities, libraries are providing spaces designed for small businesses and entrepreneurs to gather, conduct market research, and access needed resources and materials. Some libraries have begun to add mobile outreach vehicles that allow for the delivery of programs and services outside of the library building.

\subsection{Technology}

Technology offered by libraries includes computers, printers, internet access, and digital access to information. Services related to technology, such as courses, workshops and other supports are also included in this dimension. Each library examined provides access to electronic resources in the form of ebooks, digital audio books, magazines and databases, while some also offer music, and movie downloads. The first ever all digital public library opened in 2013, and provides electronic resources as well as technology and staff to help citizens use the technology.

Each of the libraries examined offers computer and internet access, as well as WiFi access inside of the library during open library hours. Some libraries are offering $\mathrm{Wi}-\mathrm{Fi}$ that reaches outside of the library building to parking lots and outdoor seating areas to provide access even outside of library hours. Still others offered WiFi hotspot lending programs, which allow citizens to borrow technology to have internet access in their homes. Some libraries also offer technology and connectivity in other parts of the community, sometimes in partnership with other community organizations in fixed locations, or via buses that travel around, bringing services to those in underserved neighborhoods who cannot physically travel to the library. Some libraries offer technology such as laptops, eReaders and mp3 players that can be borrowed for set periods of time.

All libraries examined offer basic courses and workshops to teach community members how to use technology. Some libraries go beyond providing basic computer courses and offer workshops in social media applications and other technology like robots and 3D printing. Libraries are also advertising one-on-one technology consultations on their websites. They are creating programs that partner teen technology trainers with older adults, and are creating downloadable technology modules that residents can participate in at the places and times that are most convenient to them.

\subsection{Programs and services}

From involving the community in long range planning to conducting surveys and placing suggestion boxes, libraries are known for creating programs and services that address the needs of their residents.
Although the programs and services that each library offers are unique to the populations they serve, several themes emerged. The first set of services and programs discussed are those that aim to benefit all community members, followed by services aimed at adults, young adults, children and then other specific populations.

Libraries are using a variety of means to communicate what is available in the library, as well as to encourage citizens to engage in programs and services throughout their communities. Many libraries have mailing lists, email lists and events listings. They create flyers and have a web presence that announces what is happening in the library to draw citizens in. Libraries are offering services that allow patrons to receive text messages about library happenings and items due back at the library, and many are using social media like Facebook and Twitter for two-way communication - to share what happens at the library, and as a way for citizens to share their thoughts with the library. At a time when many small news outlets have gone out of business, some libraries are filling a larger void in their communities by forming partnerships to create newsletters and newspapers that list events, activities and news from throughout the community and giving residents a chance to contribute.

Some libraries engage citizens with workshops, clinics and services designed to meet their legal needs, with free virtual clinics or monthly programs that covers common legal issues. Libraries are offering passport services, notary services, and patent and trademark resources. Libraries are partnering with other local cultural organizations to offer circulating passes to places like museums, art centers and zoos, making these experiences more widely accessible to all residents of a community.

While libraries are known for arts and crafts programs for children, some are extending those programs to teens and adults as well. Libraries are being used as a place to create together in makerspaces, fab labs and digital design studios, where patrons of all ages build, explore and learn. The creation of these spaces has allowed for new programs to be offered, like workshops and classes on digital design and fabrication.

Not only are libraries offering spaces, programs and workshops to help their patrons produce, they are also offering ways for creative works to be shared with others. Some libraries are offering art gallery spaces as a way to draw community members in to the library by offering a unique experience, and to see that the library offers more than just books. Some libraries are providing platforms to curate and distribute locally produced art, music, writing and performances as part of the library collection. 
As part of knowing populations and what their needs are, libraries have begun to create specialized collections as well. Libraries circulate items like blood pressure monitors and food scales, seeds for gardening, American Girl Dolls, thermal cameras and LED Bulbs, robots, garden and power tools, among other things. Some libraries are digitizing special collections to provide access to documents that could previously only be used in the library.

Libraries are targeting adults with a number of innovative programs and services. To meet education needs, libraries are offering high school equivalency exam preparation materials, classes and programs, some are offering literacy tutoring to adults of all ages and reading levels, and some are providing access to online programs that helps citizens gain workforce skills. Libraries are also offering career transition services such as resume writing, interview skills workshops and job coaching. Others offer financial literacy services, from workshops on budgeting to individual tax help. Libraries are also starting to offer health related workshops and services. One library has partnered with the local Department of Health to locate a WIC center in their library (WIC is a program that provides vouchers for healthy food to qualifying women, infants and children). Libraries are also offering workshops on how to navigate the Health Insurance marketplace.

To meet the needs of teens, libraries are offering designated spaces where they can play games, relax with friends, get help with homework, make crafts, or engage in programs like bad movie Friday and teen battle of the books teams. Some libraries offer services to incarcerated and at risk youth like book deposits, book talks and programming. Libraries have opened branches in juvenile detention centers and programs, and offer full services to youth in custody. One library partners with the high school to create a youth entrepreneur program and youth business fair. The creation of spaces like makerspaces and digital recording studios are allowing new programming opportunities like Maker Mondays and workshops to train students to use equipment like 3D printers, cameras and editing software. Programs are allowing teens to work along-side adult mentors to learn to create using the tools and materials in the spaces. By creating these spaces specifically for the youth population, libraries are able to offer new services, workshops and programs to draw teen users in to the libraries, and provide opportunities for active learning.

Most libraries provide a dedicated children's area, offer story times for various age groups, create summer reading programs, and offer weekly events like Lego club and crafts. Some libraries are adding winter reading programs to encourage reading throughout the year, not just the summer as well as offering kindergarten boot camps to help children build social skills and make friends before they begin school. Infrastructure innovations offer opportunities for young children to learn along-side teens and adults in spaces where they have a chance to add to the conversation. Some libraries are using mobile programming in the form of busses and pop-up libraries to offer services outside of the library for children who would not normally be able to come due to transportation limitations.

Some of the most innovative practices involve offering specialized services for populations that have been identified as those most in need. These programs and services are targeting specific populations that are often left out of service plans. Specifically, we identified programs and services being offered for immigrants, people with disabilities, veterans, the homeless, and incarcerated individuals.

Many libraries are offering foreign language materials, English language courses for various levels of proficiency, and workshop and events for their immigrant patrons. Some have created resource centers specifically designed to help patrons with a range of needs, including citizenship test study materials. Libraries informal practice groups, free work and life skill development, and programs to help immigrants understand and interact with culture, government and educational services in the United States. Some also offer free legal assistance to become a citizen. Libraries are also offering computer courses, playtimes and other programs in languages other than English.

Libraries are also ensuring that disabled patrons have equal access to resources, services and programs. While many libraries offer audio books, digital audio books, and large print text, some libraries are moving toward providing more adaptive and assistive technology like screen readers, jumbo keyboards and refreshable braille displays. The libraries are also offering training and support for the assistive technology, making it possible for disables patrons to take advantage of library resources. Some libraries are offering motorized wheelchairs for patron use in the library, and some are hiring librarians focused on providing services for patrons with learning differences. They are also offering workshops and programs to raise awareness about learning differences and offer digital streaming of the programs offered.

Libraries have opened Veterans Resource Centers, spaces reserved for exclusive use by veterans. The library and volunteers offer information about benefits, resources, local services, computer use and other support for veterans in the community. Libraries have also begun to hire counselors, social workers, and outreach specialists to help community members in 
need. Some of the populations they have identified include homeless and transient populations.

Some libraries provide substantial support to incarcerated and recently released individuals. In addition to a reentry programs which provide a temporary library card and reentry guides, libraries are offering opportunities for inmates to connect with their children and loved ones through video mediated literacy programs.

\subsection{Partnerships}

From local to state level government, other community and cultural organizations, businesses and individual citizens, libraries are creating partnerships that allow them to offer new programs and services by providing funding and other resources to the library.

Many libraries have strong partnerships with the municipal government which allows them to co-create services based on community needs. Libraries work closely with both the government and the broader community to identify needs by holding public meetings, conducting interviews, hosting focus groups and conducting surveys. They are including citizens, elected officials, community leaders, board members, and employees to determine the top current and projected needs for their community and how the library can best respond to those needs. One library partnered with the local university and citizens to engage architecture students in redesigning the library. This gave the university students an opportunity to solve a real world problem while also allowing citizens input in to what their library will look and feel like.

Some libraries are partnering with other institutions to create educational opportunities for non-traditional students, such as the Microcollege program created by one library with a liberal arts college that offers a free college education to those traditionally blocked from pursuing higher education.

Another library organized meetings for business owners to work on a main street reconstruction project, and developed outlets for businesses to draw in more customers. They are also using those resources to help the local government realize a need for city planning, link them to planners, and furthering community conversations on the topic.

\subsection{Citizen engagement}

Libraries are providing information, and many are providing government resources, and spaces that can be used for forums to discuss issues pertinent to the community, like providing meeting rooms to gather input on the comprehensive plans for the community.
They are engaging citizens in the library, but also in civic endeavors.

Libraries are partnering with the local government to create electronic community bulletin boards where residents can communicate about topics ranging from community issues to the exchange of services and goods. Beyond providing spaces physically and virtually, some libraries are designing and hosting forums and programs around civic related topics, and hiring community engagement librarians. They are creating programs designed for the community to gather together to get to know one another and hosting brainstorming sessions to identify projects to help residents improve their communities. They are creating regular events like community reads projects where free copies of a specific title are provided at a number of locations around the town to stimulate conversation around shared topics. Libraries are creating pop-up programs and providing information and activities to spark conversation to support dialogue and engagement on issues that are affecting the community. The topics change as the needs of the community change and have included racism, environmental issues, and exploring identity. These events and activities are helping to build a sense of pride, trust, and stronger relationships among members of the community.

Some libraries are engaging community members by asking them to co-create information sources. One library asks community members to help place historical photographs and documents on maps to create a virtual time machine of the city, making urban history accessible to all. The same library has citizens polish machine created transcripts of oral history interviews. Other libraries are asking community members to help create collections of their own stories and memories of the community. These kinds of projects make it easier for community members to feel like they are a part of building something together.

\subsection{Integrative innovations}

Although dimensions emerged as we examined each library, it was also clear that the dimensions worked together to allow for truly integrative innovations in many of the libraries. Infrastructure, technology, citizen engagement, and partnerships allow libraries to offer new and innovative programs and services to meet the specific needs of their communities.

Libraries are creating safe spaces where teens can hang out, study and read while feeling empowered to pursue their interests. Spaces are being designed to engage teens in critical thinking, technology literacy, innovation and skill building while serving as hubs of 
out-of-school learning. The creation of such spaces is evident in many libraries, and how those spaces are being designed and implemented makes them unique. They require infrastructure changes, funding and support from partners, and input from the community members they aim to serve. Providing a space is not enough, and the planning of events, programs and services to draw the youth in often relies heavily on volunteers from the community. The creation of spaces where teens have access to materials and resources for learning and to develop a love for reading, makerspaces stocked with technology and supplies, digital recording studios with the latest audio/visual equipment does not come without financial costs. Without support from the local government, businesses and other community organizations, many of these spaces would not exist.

As noted earlier, libraries are creating spaces for innovation, collaboration and hands on learning that are open to adults and younger children as well. These spaces are being created to provide an alternative to traditional library services in support of the libraries missions to engage citizens in lifelong learning. Libraries are hosting open workshop times, classes, meetups and certification sessions. They are being built with patron feedback, support by municipal administration and other community organizations, as well as staff in the libraries. These spaces are receiving extensive volunteer support from the community as well.

One library, in collaboration with the local government, school district, and electric company, created a Smart City Education Center where children can learn about sustainability and renewable energy, and how to make smart choices. A curriculum was developed for teachers to use in schools. This space offers murals, activities, books and other materials to teach students about clean and renewable energy, and how to make smart energy choices for a better future, one of the tenants of the city's smart plan.

\section{Conclusions}

Our study shows that public libraries are already engaging citizens in innovative ways and some of these new programs and services could foster smart community initiatives by providing adequate infrastructure and the necessary skills. Taking all these innovations together, there seems to be a path for public libraries to keep evolving and become essential for a great variety of smart efforts. In fact, moving from providing technology to teaching citizens how to use it helps create a technology literate community, which could be the basis of new programs and services for all citizens and encourage a sense of community.
In addition, our findings indicate that libraries are consciously working to become a third space; a place for learning in multiple domains and that provides resources in the form of both materials and active learning opportunities. In fact, libraries are helping to aid in workforce development, which in turn could help local economic growth. There are many other concrete examples of how libraries are already contributing to community aspects that have been consistently related to smartness. Sustainability, engagement, economic development, and the use of new technologies are just a few of the aspects in which public libraries will potentially play a very important role as catalysts for smart community initiatives.

Finally, we recognize that much is still needed in terms of empirical research about this topic. Learning about the existing and potential benefits, costs, risks, challenges, and unintended consequences for public libraries increasing their involvement in their smart community initiatives as well as understanding the relationship between local governments and public libraries in the development of smart communities are only two potential areas of further research. From a practical point of view, our study also shows the importance for public managers to understand and recognize the potential of public libraries in smart community projects and to consider them as a key actor in the governance of the smart community.

\section{References}

[1] I. Calzada, "The Techno-Politics of Data and Smart Devolution in City-Regions: Comparing Glasgow, Bristol, Barcelona, and Bilbao," Systems, vol. 5, no. 1, p. 18, 2017.

[2] A.-v. Anttiroiko, "City-as-a-Platform: Towards citizencentred platform governance," in RSA Winter Conference 2016 on New Pressures on Cities and Regions, vol. 8, pp. 1-27, 2016.

[3] E. Almirall, M. Lee, and A. Majchrzak, "Open innovation requires integrated competition-community ecosystems: Lessons learned from civic open innovation," Business Horizons, vol. 57, no. 3, pp. 391400, 2014.

[4] G. B. Burke, A. Kowlowitz, T. A. Pardo, and M. Sutherland, "Enabling Open Government for All : A Road Map for Public Libraries," tech. rep.

[5] E. P. Goodman, "Smart Cities Meet Anchor Institutions: the Case of Broadband and the Public Library," Fordham Urban Law Journal, vol. 41, no. 5, pp. 1665 1694, 2014.

[6] A. Jerkov, A. Sofronijevic, and D. K. Stanisic, "Smart and sustainable library: Information literacy hub of a new city," in Communications in Computer and Information Science, vol. 552, pp. 350-359, 2015. 
[7] D. Maurrasse and J. B. Bliss, "Comprehensive Approaches to Urban Development: Gentrification , Community, and Business in Harlem, New York," Northwestern Journal of Law and Social policy, vol. 1, no. $1,2006$.

[8] H. Chourabi, T. Nam, S. Walker, J. R. Gil-Garcia, S. Mellouli, K. Nahon, T. A. Pardo, and H. J. Scholl, "Understanding smart cities: An integrative framework," Proceedings of the Annual Hawaii International Conference on System Sciences, pp. 22892297, 2012.

[9] A. Meijer and M. P. Rodríguez Bolívar, "Governing the smart city: a review of the literature on smart urban governance," International Review of Administrative Sciences, vol. 82, pp. 392-408, 62016.

[10] A. Cocchia, "Smart and Digital City: A Systematic Literature Review," in Smart City: How to Create Public and Economic Value with High Technology in Urban Space (R. P. Dameri and C. Rosenthal-Sabroux, eds.), pp. 13-43, 2014.

[11] M. Gasco , "What makes a city smart? Lessons from Barcelona," Proceedings of the Annual Hawaii International Conference on System Sciences, vol. 2016-March, pp. 2983-2989, 2016.

[12] O. Soderstrom, T. Paasche, and F. Klauser, "Smart cities as corporate storytelling," City, vol. 18, pp. 307320, 52014.

[13] K. C. Desouza and T. H. Flanery, "Designing, planning, and managing resilient cities: A conceptual framework," Cities, vol. 35, pp. 89-99, 122013.

[14] P. Berrone, J. E. Ricart, C. Carrasco, and A. Duch, "IESE Cities in Motion Index 2018," tech. rep., IESE Business School, 2018.

[15] J. R. Gil-Garcia, J. Zhang, and G. Puron-Cid, "Conceptualizing smartness in government: An integrative and multi-dimensional view," Government Information Quarterly, vol. 33, no. 3, pp. 524-534, 2016.

[16] R. Giffinger, C. Fertner, H. Kramar, R. Kalasek, N. Pichler-Milanovic, and E. Meijers, "Smart cities Ranking of European medium-sized cities," Tech. Rep. October, 2007.

[17] M. Gasco -Hernandez, "Building a smart city," Communications of the ACM, vol. 61, pp. 50-57, 3 2018.

[18] R. Giffinger and H. Gudrun, "Smart cities ranking: an effective instrument for the positioning of the cities?," ACE: Architecture, City and Environment, 22010.

[19] A. Gray, "These are the best-run cities in the world," 2017.

[20] P. Hall, "Creative Cities and Economic Development,"
Urban Studies, vol. 37, pp. 639-649, 42000.

[21] G. Kuk and M. Janssen, "The Business Models and Information Architectures of Smart Cities," Journal of Urban Technology, vol. 18, pp. 39-52, 42011.

[22] M. Gasco , B. Trivellato, and D. Cavenago, "How Do Southern European Cities Foster Innovation? Lessons from the Experience of the Smart City Approaches of Barcelona and Milan," in Smarter as the New Urban Agenda (J. R. Gil-Garcia, T. Pardo, and T. Nam, eds.), pp. 191-206, Cham: Springer International Publishing, 2016.

[23] A. Meijer, "Datapolis: A Public Governance Perspective on Smart Cities," Perspectives on Public Management and Governance, 122017.

[24] M. P. Rodríguez Bolívar, "Governance Models and Outcomes to Foster Public Value Creation in Smart Cities," in Proceedings of the 18th Annual International Conference on Digital Government Research - dg.o '17, (New York, New York, USA), pp. 521-530, ACM Press, 2017.

[25] T. Nam and T. A. Pardo, "Conceptualizing smart city with dimensions of technology, people, and institutions," in Proceedings of the 12th Annual International Digital Government Research Conference on Digital Government Innovation in Challenging Times - dg.o '11, (New York, New York, USA), p. 282, ACM Press, 2011.

[26] J. R. Gil-Garcia, T. A. Pardo, and T. Nam, "What makes a city smart? Identifying core components and proposing an integrative and comprehensive conceptualization," Information Polity, vol. 20, pp. 6187, 72015.

[27] United Nations Statistics Division (UNSD), "United Nations Demographic Yearbook 2005,” 2008.

[28] M. Angelidou, "Smart city policies: A spatial approach," Cities, vol. 41, pp. S3-S11, 72014.

[29] P. Traverso, "Keynote abstract: From smart cities to smart communities: The case of children's independent mobility," in 2015 10th International Workshop on Semantic and Social Media Adaptation and Personalization (SMAP), pp. xv-xv, IEEE, 112015.

[30] M. Gurstein, "What is Community Informatics (and Why Does It Matter)?," 122007.

[31] M. Gurstein, "Smart Cities vs. Smart Communities: Empowering Citizens not Market Economics," The Journal of Community Informatics, vol. 10, no. 3, 2014.

[32] A. Coe, G. Paquet, and J. Roy, "E-Governance and Smart Communities," Social Science Computer Review, vol. 19, pp. 80-93, 22001. 
[33] Initiative for a Competitive Inner City and CEOs for Cities, "Leveraging colleges and universities for urban economic revitalization: An action agenda," tech. rep., 2002.

[34] I. Harkavy, "Engaging Urban Universities as Anchor Institutions for Health Equity," American Journal of Public Health, vol. 106, pp. 2155-2157, 122016.

[35] M. M. Ehlenz, "Defining University Anchor Institution Strategies: Comparing Theory to Practice," Planning Theory \& Practice, vol. 19, pp. 74-92, 12018.

[36] L. H. Mandel, N. D. Alemanne, and C. R. McClure, "Rural anchor institution broadband connectivity," in Proceedings of the 2012 iConference on - iConference '12, (New York, New York, USA), pp. 136-144, ACM Press, 2012.

[37] A. Cocciolo, "Public Libraries and PBS Partnering to Enhance Civic Engagement: A Study of a Nationwide Initiative," Public Library Quarterly, vol. 32, pp. 1-20, 12013.

[38] R. Young, "More Than Just Books: The Role of Public Libraries in Building Community and Promoting Civic Engagement," National Civic Review, vol. 101, pp. 3032, 122012

[39] S. Hildreth, "Inspiring Libraries as Community Anchors," National Civic Review, vol. 101, pp. 44-47, 122012.

[40] D. P. Moxley and J. M. Abbas, "Envisioning Libraries as Collaborative Community Anchors for Social Service Provision to Vulnerable Populations," Practice, vol. 28, pp. 311-330, 102016.

[41] N. Lenstra, "Lets Move! Fitness Programming in Public Libraries," Public Library Quarterly, pp. 1-20, 5 2017.

[42] K. R. Aldrich, "Pre-K Partnership: How One Library and One Public School Increased Parent Engagement," Children and Libraries, vol. 15, p. 21, 62017.

[43] R. Oldenburg, The great good place : cafes, coffee shops, community centers, beauty parlors, general stores, bars, hangouts, and how they get you through the day. Paragon House, 1989.

[44] R. Oldenburg, Celebrating the third place : inspiring stories about the "great good places" at the heart of our communities. Marlowe \& Co, 2001.

[45] B. Real, J. C. Bertot, and P. T. Jaeger, "Rural Public Libraries and Digital Inclusion: Issues and Challenges," Information Technology and Libraries, vol. 33, p. 6, 3 2014.

[46] J. C. Bertot, B. Real, and P. T. Jaeger, "Public Libraries Building Digital Inclusive Communities: Data and Findings from the 2013 Digital Inclusion Survey," The Library Quarterly, vol. 86, pp. 270-289, 72016.

[47] Schools Health \& Libraries Broadband (SHBL) Coalition, "Community anchor institutions and residential broadband adoption," tech. rep., Benton Foundation, Evanton, 2016.

[48] N. D. Alemanne, L. H. Mandel, and C. R. McClure, "The Rural Public Library as Leader in Community. 